\title{
Serosal-to-mucosal urea flux across the isolated ruminal epithelium is mediated via urea transporter-B and aquaporins when Holstein calves are abruptly changed to a moderately fermentable diet
}

\author{
M. E. Walpole, ${ }^{*}$ B. L. Schurmann, ${ }^{*}$ P. Górka, † G. B. Penner, ${ }^{*}$ M. E. Loewen, $\ddagger$ and T. Mutsvangwa* \\ *Department of Animal and Poultry Science, University of Saskatchewan, Saskatoon, Saskatchewan, Canada S7N 5A8 \\ tDepartment of Animal Nutrition and Feed Management, University of Agriculture in Krakow, Krakow, Poland \\ ‡Department of Biomedical Sciences, Western College of Veterinary Medicine, University of Saskatchewan, Saskatoon, Saskatchewan, \\ Canada S7N 5B4
}

\section{ABSTRACT}

Urea transport (UT-B) proteins are known to facilitate urea movement across the ruminal epithelium; however, other mechanisms may be involved as well because inhibiting UT-B does not completely abolish urea transport. Of the aquaporins (AQP), which are a family of membrane-spanning proteins that are predominantly involved in the movement of water, AQP-3, AQP-7, and AQP-10 are also permeable to urea, but it is not clear if they contribute to urea transport across the ruminal epithelium. The objectives of this study were to determine (1) the functional roles of AQP and UT-B in the serosal-to-mucosal urea flux $\left(\mathrm{J}_{\mathrm{sm} \text {-urea }}\right)$ across rumen epithelium; and (2) whether functional adaptation occurs in response to increased diet fermentability. Twenty-five Holstein steer calves $(\mathrm{n}=5)$ were assigned to a control diet (CON; $91.5 \%$ hay and $8.5 \%$ vitamin and mineral supplement) or a medium grain diet (MGD; $41.5 \%$ barley grain, $50 \%$ hay, and $8.5 \%$ vitamin and mineral) that was fed for 3, 7, 14, or $21 \mathrm{~d}$. Calves were killed and ruminal epithelium was collected for mounting in Ussing chambers under shortcircuit conditions and for analysis of mRNA abundance of UT-B and AQP-3, AQP-7, and AQP-10. To mimic physiologic conditions, the mucosal buffer $(\mathrm{pH} 6.2$ ) contained no urea, whereas the serosal buffer ( $\mathrm{pH} 7.4)$ contained $1 \mathrm{~m} M$ urea. The fluxes of ${ }^{14} \mathrm{C}$-urea $\left(\mathrm{J}_{\mathrm{sm} \text {-urea }}\right.$; $26 \mathrm{kBq} / 10 \mathrm{~mL})$ and ${ }^{3} \mathrm{H}$-mannitol $\left(\mathrm{J}_{\text {sm-mannitol }} ; 37 \mathrm{kBq} / 10\right.$ $\mathrm{mL}$ ) were measured, with $\mathrm{J}_{\text {sm-mannitol }}$ being used as an indicator of paracellular or hydrophilic movement. Serosal addition of phloretin $(1 \mathrm{~m} M)$ was used to inhibit UT-B-mediated urea transport, whereas $\mathrm{NiCl}_{2}(1 \mathrm{mM})$ was used to inhibit AQP-mediated urea transport. Across treatments, the addition of phloretin or $\mathrm{NiCl}_{2}$ reduced the $\mathrm{J}_{\mathrm{sm} \text {-urea }}$ from 116.5 to 54.0 and $89.5 \mathrm{nmol} /$ $\left(\mathrm{cm}^{2} \times \mathrm{h}\right)$, respectively. When both inhibitors were

Received August 19, 2014.

Accepted October 21, 2014

${ }^{1}$ Corresponding author: tim.mutsvan@usask.ca added simultaneously, $\mathrm{J}_{\text {sm-urea }}$ was further reduced to $36.8 \mathrm{nmol} /\left(\mathrm{cm}^{2} \times \mathrm{h}\right)$. Phloretin-sensitive and $\mathrm{NiCl}_{2^{-}}$ sensitive $\mathrm{J}_{\text {sm-urea }}$ were not affected by diet. The $\mathrm{J}_{\text {sm-urea }}$ tended to increase linearly as the duration of adaptation to MGD increased, with the lowest $\mathrm{J}_{\text {sm-urea }}$ being observed in animals fed CON $\left[107.7 \mathrm{nmol} /\left(\mathrm{cm}^{2} \times \mathrm{h}\right)\right]$ and the highest for those fed the MGD for $21 \mathrm{~d}$ [144.2 $\left.\mathrm{nmol} /\left(\mathrm{cm}^{2} \times \mathrm{h}\right)\right]$. Phloretin-insensitive $\mathrm{J}_{\text {sm-urea }}$ tended to increase linearly as the duration of adaptation to MGD increased, whereas $\mathrm{NiCl}_{2}$-insensitive $\mathrm{J}_{\text {sm-urea }}$ tended to be affected by diet. Gene transcript abundance for AQP-3 and UT-B in ruminal epithelium increased linearly as the duration of MGD adaptation increased. For AQP-7 and AQP-10, gene transcript abundance in animals that were fed the MGD was greater compared with that of CON animals. These results demonstrate that both AQP and UT-B play significant functional roles in urea transport, and they may play a role in urea transport during dietary adaptation to fermentable carbohydrates.

Key words: aquaporin, ruminal epithelium, urea transporter, Ussing chamber

\section{INTRODUCTION}

Ruminants are able to maintain a positive nitrogen (N) balance by recycling BUN to the gastrointestinal tract (GIT), a physiological mechanism that is referred to as urea-nitrogen salvaging (UNS; Fuller and Reeds, 1998). Various studies (e.g., Lobley et al., 2000; Marini et al., 2004; Gozho et al., 2008; Doranalli et al., 2011) have demonstrated that substantial amounts of $\mathrm{N}$ transit the urea- $\mathrm{N}$ pool daily in ruminants, and reported data indicate that 40 to $80 \%$ of endogenously produced urea- $\mathrm{N}$ is returned to the GIT (Harmeyer and Martens, 1980; Lapierre and Lobley, 2001). Urea can enter all major GIT compartments directly across the GIT wall (Siddons et al., 1985; Egan et al., 1986), but the reticulo-rumen is the GIT compartment where most of the use of recycled urea- $\mathrm{N}$ for microbial protein 
synthesis occurs (Lapierre and Lobley, 2001). Urea$\mathrm{N}$ that passes into the reticulo-rumen provides $\mathrm{N}$ for microbial growth, thus contributing AA to the animal when ruminal microbes pass out of the rumen and are subsequently digested at the small intestine (Lobley et al., 2000).

Ritzhaupt et al. (1997, 1998) demonstrated the presence of carrier-mediated, facilitative urea transporter (UT) proteins in ovine ruminal and colonic epithelia, which are now known to allow the rapid movement of urea down a concentration gradient from blood into the GIT. These UT are derived from 2 major gene variants: UT-A and UT-B (Stewart et al., 2005), and mRNA expression for UT-B has been characterized in ruminal epithelium (Marini and Van Amburgh, 2003; Marini et al., 2004; Stewart et al., 2005). Various researchers (Stewart et al., 2005; Abdoun et al., 2010; Doranalli et al., 2011) showed that adding phloretin (an inhibitor of UT-B function) to mounted ruminal epithelia in Ussing chambers reduced the serosal-to-mucosal urea flux $\left(\mathbf{J}_{\text {sm-urea }}\right)$, indicating that UT-B have a functional role in UNS; however, a variable portion of $\mathrm{J}_{\text {sm-urea }}$ (up to $50 \%$ ) was not phloretin-inhibitable, which suggests that other phloretin-insensitive mechanisms for urea transport exist in ruminal epithelia. Possible alternative transport mechanisms are the aquaporins (AQP), a family of membrane-spanning proteins that are predominantly involved in the movement of water and are expressed in many tissues (including the GIT) of nonruminants (Ma and Verkman, 1999). Some AQP - the aquaglyceroporins (AQP-3, 7, 9, and 10)-have been shown to be permeable to urea in nonruminants (Rojek et al., 2008). Røjen et al. (2011) showed that AQP-3, 7, and 10 are expressed in bovine ruminal epithelium; however, surprisingly, the mRNA expression of these AQP was greater in cows fed a high-N diet compared with those fed a low-N diet. This was discordant with the increased transepithelial urea transfer observed when dietary $\mathrm{N}$ content was decreased in the same study (Kristensen et al., 2010), leading the authors to suggest that AQP had limited involvement in transepithelial urea transport. Although this study showed no relationship between the mRNA abundance or protein expression of AQP-3, 7, and 8 and ruminal epithelial permeability to urea, no studies to our knowledge have examined the functional roles of these AQP in urea movement across the ruminal epithelium. In addition, it is unknown if AQP and UT-B expression is regulated in an integrated manner that is designed to conserve $\mathrm{N}$ via UNS.

It is well established that the entry of urea-N into the GIT increases when ruminants are fed diets high in ruminally fermentable carbohydrate (Huntington and Archibeque, 1999) or when carbohydrate digestion is shifted from the small intestine to the rumen via grain processing (Delgado-Elorduy et al., 2002; Theurer et al., 2002). Under these feeding conditions, improved ammonia-N uptake by ruminal microbes decreases its portal absorption and, consequently, BUN concentrations decrease. Because the movement of urea-N from blood across the ruminal wall into the lumen is positively correlated with BUN concentration (Vercoe, 1969; Sunny et al., 2007), lower BUN concentrations do not provide a favorable concentration gradient; thus, it is plausible that the increased passage of urea- $\mathrm{N}$ into the rumen when energy availability is increased could be mediated via changes in the expression of membrane proteins such as UT-B and AQP, which would result in changes in ruminal epithelial permeability to ureaN (Abdoun et al., 2010). In support of this assertion, the addition of short-chain fatty acids at a luminal $\mathrm{pH}$ of 6.4 (which is indicative of high rates of ruminal carbohydrate fermentation) to ruminal epithelial tissue mounted in Ussing chambers resulted in a 4-fold increase in $\mathrm{J}_{\text {sm-urea }}$. What is unknown, however, is whether UT-B and AQP mediate the known effects of ruminal carbohydrate digestion on urea- $\mathrm{N}$ passage from blood into the rumen.

The aim of the current study was to determine the relative functional roles of UT-B and AQP in urea transport across the ruminal epithelium and to determine if UT-B and AQP mediate the known effects of ruminal carbohydrate digestion on $\mathrm{J}_{\text {sm-urea }}$ after an abrupt change in diet fermentability. Our hypothesis was that UT-B and AQP play functional roles in UNS, and that the increase in $\mathrm{J}_{\text {sm-urea }}$ that has been observed in ruminants fed more fermentable carbohydrates is mediated via changes in UT-B and AQP function.

\section{MATERIALS AND METHODS}

\section{Animals, Experimental Treatments, and Feeding Management}

The detailed descriptions of experimental procedures are outlined in Schurmann (2014). Briefly, 25 Holstein steer calves were used in this study. Steer calves (BW $=213 \pm 23.0 \mathrm{~kg}$ ) were housed in the Livestock Research Building at the University of Saskatchewan, and their use in this experiment was preapproved by the University of Saskatchewan Animal Care Committee (UCACS Protocol No. 20100021). Before the beginning of the experiment, calves were fed a high forage diet (91.5\% grass hay and $8.5 \%$ mineral supplement). At the beginning of the experiment, calves were weighed and then blocked by BW into 5 blocks of 5 animals per block. Within each block, calves were then assigned to 1 of 5 dietary treatments, which consisted of a control 
diet $(\mathbf{C O N} ; 91.5 \%$ hay and $8.5 \%$ vitamin and mineral supplement; $10.6 \%$ CP, $4.1 \%$ starch, $48.4 \% \mathrm{NDF}$ ) or a moderate grain diet (MGD; $41.5 \%$ barley grain, $50 \%$ hay, and $8.5 \%$ vitamin and mineral; $11.4 \% \mathrm{CP}, 24.6 \%$ starch, 33.5\% NDF) that was fed for 3, 7, 14, or $21 \mathrm{~d}$ (designated G3, G7, G14, and G21, respectively). Because only one animal could be killed per day to obtain tissues for ex vivo studies, the initiation of the feeding of experimental diets to individual animals within each block had to be staggered over time to achieve the desired lengths of dietary exposure (i.e., $0,3,7,14$, or 21 d). Within each block, the order of killing was random. This experimental design ensured that the order of killing was balanced among treatments over time. Animals were fed at $2.25 \%$ of BW (DMI $=4.8 \pm 0.2 \mathrm{~kg} / \mathrm{d})$ once daily at $0800 \mathrm{~h}$ and had free access to water throughout the duration of the experiment.

\section{Flux Measurements in Ussing Chambers}

After the desired length of dietary exposure, calves were killed ( 1 per day) by captive bolt stunning followed by pithing and exsanguination at $2 \mathrm{~h}$ after feeding, allowing time for fermentation to occur in the reticulo-rumen after the morning feeding (Robinson et al., 1997). Within 2 to 3 min of exsanguination, the digestive tract was removed from the abdominal cavity and a $300-\mathrm{cm}^{2}$ piece of ruminal wall was removed from the caudaldorsal blind sac. This area of the ruminal epithelium was chosen because of its uniformity in papillae size and density. The ruminal wall was washed in a physiological buffer solution until clean. The physiological buffer solution $\left(\mathrm{pH} 7.4 ; 38^{\circ} \mathrm{C}\right)$ was continuously gassed with carbogen $\left(95 \% \mathrm{O}_{2} / 5 \% \mathrm{CO}_{2}\right)$ and it contained $(\mathrm{mM}): 1$ $\mathrm{CaCl}_{2} \cdot 2 \mathrm{H}_{2} \mathrm{O}, 1.25 \mathrm{MgCl}_{2} \cdot 6 \mathrm{H}_{2} \mathrm{O}, 15.6 \mathrm{NaCl}, 5.5 \mathrm{KCl}, 0.6$ $\mathrm{NaH}_{2} \mathrm{PO}_{4} \cdot \mathrm{H}_{2} \mathrm{O}, 2.4 \mathrm{Na}_{2} \mathrm{HPO}_{4} \cdot 2 \mathrm{H}_{2} \mathrm{O}, 10$ acetic acid, 5 Na-D/L-lactate (60\%), 1 L-glutamine, 10 HEPES-free acid, $10 \mathrm{Na}$-propionate, 10 Na-butyrate, $10 \mathrm{NaOH}$, and $24 \mathrm{NaHCO}_{3}$. After washing, the ruminal wall was gently stripped of the underlying muscular layer. The epithelium was then placed in the physiological buffer solution and transported to the laboratory $(\sim 5 \mathrm{~min})$. The physiological buffer solution was continuously gassed with carbogen during tissue transport. Upon arrival at the laboratory, ruminal epithelia were cut into strips and placed between 2 halves of an Ussing chamber with an exposed surface area of $1.43 \mathrm{~cm}^{2}$. For each steer, 6 Ussing chambers were used for in vitro studies. Ruminal epithelia were bathed in $10 \mathrm{~mL}$ of isolated incubation buffer solutions on both the serosal and mucosal sides. The incubation buffer solution contained $(\mathrm{m} M)$ : $1 \mathrm{CaCl}_{2} \cdot 2 \mathrm{H}_{2} \mathrm{O}, 1 \mathrm{MgCl}_{2} \cdot 6 \mathrm{H}_{2} \mathrm{O}, 2 \mathrm{Na}_{2} \mathrm{HPO}_{4} \cdot 2 \mathrm{H}_{2} \mathrm{O}, 1$ $\mathrm{NaH}_{2} \mathrm{PO}_{4} \cdot \mathrm{H}_{2} \mathrm{O}, 1$ phenyl-phosphorodiamidate (urease inhibitor; Alfa Aesar, Ward Hill, MA), 5 butyric acid,
$60 \mathrm{NaCl}, 5 \mathrm{KCl}, 10$ glucose, $25 \mathrm{Na}$-acetate $\cdot 3 \mathrm{H}_{2} \mathrm{O}, 15$ Na-gluconate, $10 \mathrm{Na}$-propionate, and $25 \mathrm{NaHCO}_{3}$ (Abdoun et al., 2010). Antibiotics (penicillin G sodium salt, $60 \mathrm{mg} / \mathrm{L}$; kanamycin sulfate, $100 \mathrm{mg} / \mathrm{L}$; and flurocytosine, $50 \mathrm{mg} / \mathrm{L}$ ) were also added to the incubation buffer solution to inhibit urease activity (Doranalli et al., 2011). Unless otherwise stated, all chemicals were purchased from Sigma Aldrich (St. Louis, MO). Serosal and mucosal buffer solutions were adjusted to $\mathrm{pH} 7.4$ and 6.4, respectively, using $1 \mathrm{~m} M \mathrm{NaOH}$ or $1 \mathrm{~m} M \mathrm{HCl}$, to mimic in vivo physiological conditions. A mucosal $\mathrm{pH}$ of 6.4 was chosen because it is indicative of high rates of ruminal carbohydrate fermentation and preliminary studies with bovine ruminal epithelia showed that maximal $\mathrm{J}_{\text {sm-urea }}$ was achieved at that $\mathrm{pH}$ (M. E. Walpole, unpublished data). In addition, Abdoun et al. (2010) observed that $\mathrm{J}_{\text {sm-urea }}$ in isolated ovine ruminal epithelia was maximal at that $\mathrm{pH}$. Serosal and mucosal incubation buffer solutions were mixed using gas lift $\left(95 \% \mathrm{O}_{2} / 5 \% \mathrm{CO}_{2}\right)$ and were maintained at $38^{\circ} \mathrm{C}$ using water-jacket reservoirs. A computer-controlled voltageclamp system (VCC MC6; Physiologic Instruments, San Diego, CA) was used to maintain the ruminal epithelia under short-circuit conditions. Transepithelial conductance $\left(\mathbf{G}_{\mathbf{t}}\right)$ was measured every $6 \mathrm{~s}$, and mean Gt values were then calculated for each flux period (Doranalli et al., 2011).

For each calf, 20 min was allowed for the stabilization of electrophysiology before flux measurements were initiated. For the measurement of serosal-to-mucosal urea $\left(\mathrm{J}_{\text {sm-urea }}\right)$ and mannitol $\left(\mathbf{J}_{\text {sm-mannitol }}\right)$ fluxes, a solution that was spiked with ${ }^{14} \mathrm{C}$-urea $(26 \mathrm{kBq}$; Perkin Elmer, Waltham, MA) and ${ }^{3} \mathrm{H}$-mannitol (37 kBq; Perkin Elmer) was then added to the serosal side to achieve final concentrations of $1 \mathrm{mM}$ for both urea and mannitol. Mannitol was used to determine the magnitude of paracellular pathways (Stewart et al., 2005; Abdoun et al., 2010). Because urea was not added to the mucosal side, a serosal-to-mucosal concentration gradient existed. The rationale for this approach was 2-fold: (1) urea that is secreted into the rumen from the bloodstream is rapidly degraded by epimural ureolytic bacteria, such that ruminal fluid typically does not contain urea (Muscher et al., 2010); and (2) previous studies have demonstrated that a serosal-to-mucosal urea concentration gradient facilitates the movement of urea from the bloodstream into the rumen (Vercoe, 1969; Sunny et al., 2007). Our laboratory has used a similar approach previously (Doranalli et al., 2011). A serosal urea concentration of $1 \mathrm{~m} M$ was used because previous studies (Abdoun et al., 2010; Doranalli et al., 2011) have clearly shown that such a concentration can elicit transport changes under Ussing chamber conditions. After the addition of isotopic tracers, $30 \mathrm{~min}$ was allowed for iso- 
tope equilibration before the administration of in vitro treatments. Individual ruminal epithelia $(\mathrm{N}=6, \mathrm{n}=2)$ were assigned to 1 of 3 ex vivo treatments, which were control (no inhibitor added) or the addition of phloretin or $\mathrm{NiCl}_{2}$. Phloretin and $\mathrm{NiCl}_{2}$ were dissolved in ethanol and were added to the serosal and mucosal buffers to achieve a final concentration of $1 \mathrm{~m} M$, with an equivalent volume of ethanol being added to the serosal side for the control epithelia. Phloretin (Stewart et al., 2005; Abdoun et al., 2010) and $\mathrm{NiCl}_{2}$ (MacIver et al., 2009) are inhibitors of UT and AQP function, respectively, and were used to determine inhibitor-sensitive $\mathrm{J}_{\text {sm-urea }}$. After the addition of inhibitors, an additional $15 \mathrm{~min}$ was allowed for inhibitor equilibration before $\mathrm{J}_{\mathrm{sm} \text {-urea }}$ and $\mathrm{J}_{\mathrm{sm} \text {-mannitol }}$ across ruminal epithelia were measured during a 30-min flux period (flux period 1). Subsequently, a second 30-min flux period (flux period 2) was performed after $1 \mathrm{mM} \mathrm{NiCl}{ }_{2}$ was added to the chambers previously treated with $1 \mathrm{~m} M$ phloretin, and vice versa. This was done to determine the combined effects of phloretin and $\mathrm{NiCl}_{2}$ on $\mathrm{J}_{\text {sm-urea }}$.

\section{Tissue Collection and mRNA Expression Analysis}

Simultaneously to the collection of ruminal epithelial tissue for Ussing chamber experiments, ruminal epithelial tissue samples were also collected from the caudaldorsal sac for gene expression measurements. Ruminal epithelial tissue was washed 3 times in ice-cold PBS solution, transferred into a container filled with RNAlater (Sigma-Aldrich, Oakville, ON, Canada), temporarily stored at $4^{\circ} \mathrm{C}$ for $24 \mathrm{~h}$, before being frozen at $-20^{\circ} \mathrm{C}$ until analysis for UT-B, and AQP-3, 7, and 10 mRNA abundance. Briefly, tissue samples were homogenized and RNA was then extracted using Trizol (Invitrogen, Burlington, ON, Canada) as described by Chomczynski and Sacchi (1987). The RNA concentration was determined by measuring the absorbance at 260 and 280 nm using a NanoDrop (ND-1000, NanoDrop Technologies, Wilmington, DE). Quantitative real-time PCR was conducted using a Mx3005 real-time PCR machine (Agilent, Mississauga, ON, Canada) with a 10-min preincubation at $95^{\circ} \mathrm{C}$ followed by 40 cycles consisting of $15 \mathrm{~s}$ at $95^{\circ} \mathrm{C}$ and $60 \mathrm{~s}$ at $60^{\circ} \mathrm{C}$. All samples were analyzed in duplicate. The primers used for UT-B, and AQP-3, 7, and 10 have been reported previously (Røjen et al., 2011). The threshold cycle (CT) was deemed to be the point at which the fluorescent signal of the PCR product crossed the threshold line. The average CT for each cow and gene was compared with each cow's respective average CT for the housekeeping gene (GAPDH; AB09934) by subtracting the CT of GAPDH from the $\mathrm{CT}$ of the target gene to calculate $\triangle \mathrm{CT}$. To compare the expression of genes between treatments, one calf from the control treatment was selected at random and used as the calibrator. The $\Delta \mathrm{CT}$ of this animal was used as a reference value to calculate $\Delta \Delta \mathrm{CT}$, which generated a $\Delta \Delta \mathrm{CT}$ value of 0 for this calibrator animal. Fold changes in target gene expression were then calculated as $2^{-\Delta \Delta \mathrm{CT}}$ (Livak and Schmittgen, 2001; Ontsouka et al., 2004).

\section{Collection and Analysis of Ruminal Fluid and Blood}

Ruminal contents were collected at slaughter from the caudal-dorsal blind sac and strained through 2 layers of cheesecloth to obtain ruminal fluid. A $10-\mathrm{mL}$ sample was preserved with $2 \mathrm{~mL}$ of $1 \%$ sulfuric acid for ruminal $\mathrm{NH}_{3}-\mathrm{N}$ analysis. Samples were stored at $-20^{\circ} \mathrm{C}$ until analysis. Ruminal $\mathrm{NH}_{3}-\mathrm{N}$ was determined using a phenol-hypochlorite assay (Broderick and Kang, 1980). Blood samples were collected by jugular venipuncture into 6-mL EDTA-coated Vacutainer tubes (Becton Dickinson, Franklin Lakes, NJ) 5 min before slaughter. Samples were placed on ice until being centrifuged at $3,000 \times g$ for $15 \mathrm{~min}$ at $4^{\circ} \mathrm{C}$. Serum was separated and frozen at $-20^{\circ} \mathrm{C}$ until analysis. Serum was analyzed for urea-N using the diacetyl monoxime method (Marsh et al., 1957) using a commercial kit (Stanbio Urea Nitrogen Kit, Procedure No. 0580; Stanbio Laboratories, Boerne, TX).

\section{Calculations and Statistical Analysis}

All flux, electrophysiology, and mRNA abundance data were first analyzed using the mixed procedure of SAS version 9.2 (SAS Institute Inc., Cary, NC) with block and treatment (CON, G3, G7, G14, G21) considered fixed effects and calf as random. For this analysis, sub-treatment data were used to determine the pathway of $\mathrm{J}_{\text {sm-urea }}$ and $\mathrm{J}_{\text {sm-mannitol }}$ fluxes. The total $\mathrm{J}_{\text {sm-urea }}$ and total $\mathrm{J}_{\mathrm{sm}-\text { mannitol }}$ were obtained from chambers that had no inhibitor added to incubation buffer (control chambers). The phloretin- and $\mathrm{NiCl}_{2}$-insensitive $\mathrm{J}_{\mathrm{sm} \text {-urea }}$ and $\mathrm{J}_{\mathrm{sm} \text {-mannitol }}$ were obtained from chambers with inhibitors added to the incubation buffer during flux period 1 . The phloretin- and $\mathrm{NiCl}_{2}$-sensitive $\mathrm{J}_{\text {sm-urea }}$ and $\mathrm{J}_{\mathrm{sm} \text {-mannitol }}$ were then calculated as the difference between total flux and phloretin- and $\mathrm{NiCl}_{2}$-insensitive fluxes. Inhibitor-insensitive $\mathrm{J}_{\mathrm{sm} \text {-urea }}$ and $\mathrm{J}_{\mathrm{sm} \text {-mannitol }}$ were obtained from chambers with both inhibitors present during flux period 2. The inhibitor-sensitive $\mathrm{J}_{\text {sm-urea }}$ and $\mathrm{J}_{\mathrm{sm} \text {-mannitol }}$ were then calculated as the difference between total flux and inhibitor-insensitive fluxes. Polynomial contrasts were used to determine whether the response was linear, quadratic, or cubic ( $\mathrm{CON}$ to G21), and whether a difference existed between the CON and G21 treatments. The polynomial contrasts 
were constructed to account for unequal spacing for days on the MGD treatment.

Data for flux measurements were also analyzed using the same model described above except that sub-treatment was included in the model and the interaction between treatment and sub-treatment was assessed. The interaction between treatment and sub-treatment was not significant and was removed from the model. Data for $J_{\text {sm-mannitol }}$ did not differ by flux pathway and the data were not presented.

The relationships between $\mathrm{J}_{\mathrm{sm} \text {-urea }}$ and $\mathrm{J}_{\mathrm{sm}-\mathrm{mannitol}}$, $\mathrm{J}_{\text {sm-urea }}$ and ruminal $\mathrm{NH}_{3}-\mathrm{N}$ concentration, $\mathrm{J}_{\text {sm-urea }}$ and plasma urea- $\mathrm{N}$, and $\mathrm{J}_{\text {sm-urea }}$ and $\mathrm{G}_{\mathrm{t}}$ were tested using the correlation procedure of SAS (SAS Institute). For all analyses, significance was declared when $P<0.05$, and trends were considered when $0.05<P<0.10$.

\section{RESULTS}

\section{Diet Effects on $\mathrm{N}$ Intake and Concentrations of Ruminal $\mathrm{NH}_{3}-\mathrm{N}$ and Plasma Urea-N}

Nitrogen intake was unaffected by diet (Table 1). Increasing days on MGD altered ruminal $\mathrm{NH}_{3}-\mathrm{N}$ concentrations in a cubic manner $(P=0.004)$; however, plasma urea-N concentrations were unaffected $(P=$ 0.19 ) by dietary treatment (Table 1 ).

\section{Inhibitor and Diet Effects on Transepithelial Flux and Tissue Electrophysiological Measurements in Ussing Chambers}

Across dietary treatments, total $\mathrm{J}_{\text {sm-urea }}$ was 116.5 $\mathrm{nmol} /\left(\mathrm{cm}^{2} \times \mathrm{h}\right)$ and the addition of phloretin or $\mathrm{NiCl}_{2}$ decreased $(P<0.001)$ the $\mathrm{J}_{\text {sm-urea }}$ by 54 and $23 \%$, respectively (Figure 1). Additionally, phloretin-sensitive and $\mathrm{NiCl}_{2}$-sensitive $\mathrm{J}_{\text {sm-urea }}$ differed $(P<0.001)$ from each other. When both inhibitors were added together, total inhibitor-sensitive $\mathrm{J}_{\text {sm-urea }}$ was lower compared with $\mathrm{NiCl}_{2}$-sensitive $(P<0.001)$ or phloretin-sensitive $(P=0.028) \mathrm{J}_{\text {sm-urea }}$, decreasing $\mathrm{J}_{\text {sm-urea }}$ by $68 \%$ compared

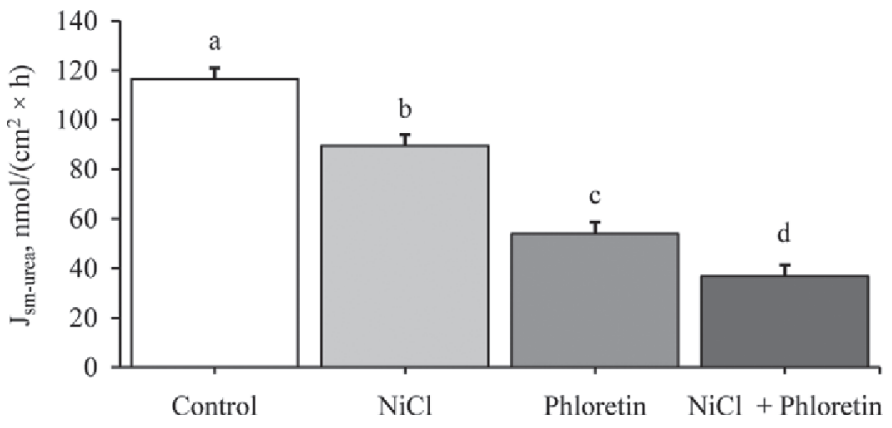

Figure 1. Control, $\mathrm{NiCl}_{2}$-insensitive, phloretin-insensitive, and total-insensitive serosal-to-mucosal fluxes of urea $\left(\mathrm{J}_{\text {sm-urea }}\right)$ across bovine ruminal epithelium collected from Holstein steer calves after an abrupt change in diet fermentability. Histograms with different letters differ $(P<0.05)$.

with total flux. The sequence of inhibitor addition had no effect on total-insensitive $\mathrm{J}_{\mathrm{sm} \text {-Urea }}(P=0.69)$. The correlation relationships between simultaneously measured $\mathrm{J}_{\mathrm{sm}-\text { urea }}$ and $\mathrm{J}_{\mathrm{sm}-\mathrm{mannitol}}$ fluxes were significant for total insensitive $(\mathrm{r}=0.89 ; P<0.001 ;$ Figure 2$)$, as well as phloretin-insensitive $(\mathrm{r}=0.91 ; P<0.001)$ and $\mathrm{NiCl}_{2}$-insensitive $(\mathrm{r}=0.9 ; P<0.001)$ fluxes (data not shown).

The effects of length of dietary adaptation on $\mathrm{J}_{\mathrm{sm}}$ urea and $\mathrm{J}_{\mathrm{sm} \text {-mannitol }}$ fluxes and tissue electrophysiological measurements are presented in Table 2 . The $\mathrm{J}_{\text {sm-urea }}(P$ $=0.096)$ and $\mathrm{J}_{\text {sm-mannitol }}(P=0.14)$ were not different between calves that received the MGD for $21 \mathrm{~d}$ (G21) and those that were not fed grain $(\mathrm{CON})$. However, $\mathrm{J}_{\text {sm-urea }}(P=0.075)$ and $\mathrm{J}_{\text {sm-mannitol }}(P=0.058)$ tended to increase linearly with increasing time on the MGD. Feeding grain tended to increase the $\mathrm{NiCl}_{2}$-sensitive $\mathrm{J}_{\mathrm{sm}}$ urea $(P=0.07)$; however, this was not observed for Ni$\mathrm{Cl}_{2}$-insensitive $\mathrm{J}_{\text {sm-urea }}(P=0.11)$. Phloretin-insensitive $\mathrm{J}_{\text {sm-urea }}$ tended to increase linearly with increasing days on the MGD $(P=0.075)$. Phloretin sensitive $\mathrm{J}_{\text {sm-urea }}$ was not affected by increasing diet fermentability $(P$ $=0.54)$. Diet had no effect on tissue conductance $\left(G_{t}\right)$; however, we detected a significant cubic effect $(P=$ 0.02 ) on short-circuit current.

Table 1. Nitrogen intake and concentrations of ruminal ammonia and serum urea- $\mathrm{N}$ in Holstein steer calves after an abrupt change in diet fermentability ${ }^{1}$

\begin{tabular}{|c|c|c|c|c|c|c|c|c|c|c|}
\hline \multirow[b]{2}{*}{ Item } & \multicolumn{5}{|c|}{ Treatment $^{1}$} & \multirow[b]{2}{*}{ SEM } & \multicolumn{4}{|c|}{ Contrast ( $P$-value $)$} \\
\hline & $\mathrm{CON}$ & G3 & G7 & G14 & G21 & & $\begin{array}{c}\mathrm{CON} \\
\text { vs. G21 }\end{array}$ & Linear & Quadratic & Cubic \\
\hline Ruminal $\mathrm{NH}_{3}-\mathrm{N}, \mathrm{mg} / \mathrm{dL}$ & 14.9 & 15.3 & 18.7 & 19.9 & 15.3 & 1.23 & 0.80 & 0.35 & $<0.01$ & 0.03 \\
\hline Serum urea-N, mg/dL & 6.42 & 6.2 & 4.69 & 5.91 & 5.17 & 0.65 & 0.19 & 0.27 & 0.47 & 0.25 \\
\hline
\end{tabular}

${ }^{1}$ Treatments: $\mathrm{CON}=$ control diet $(91.5 \%$ hay and $8.5 \%$ vitamin and mineral supplement; $10.6 \% \mathrm{CP}, 4.1 \%$ starch, $48.4 \% \mathrm{NDF}) ; \mathrm{G} 3, \mathrm{G} 7, \mathrm{G} 14$, and $\mathrm{G} 21$ = moderate grain diet (41.5\% barley grain, $50 \%$ hay, and $8.5 \%$ vitamin and mineral; $11.4 \% \mathrm{CP}, 24.6 \%$ starch, $33.5 \%$ NDF) fed for 3 , 7,14 , or 21 d., respectively. 


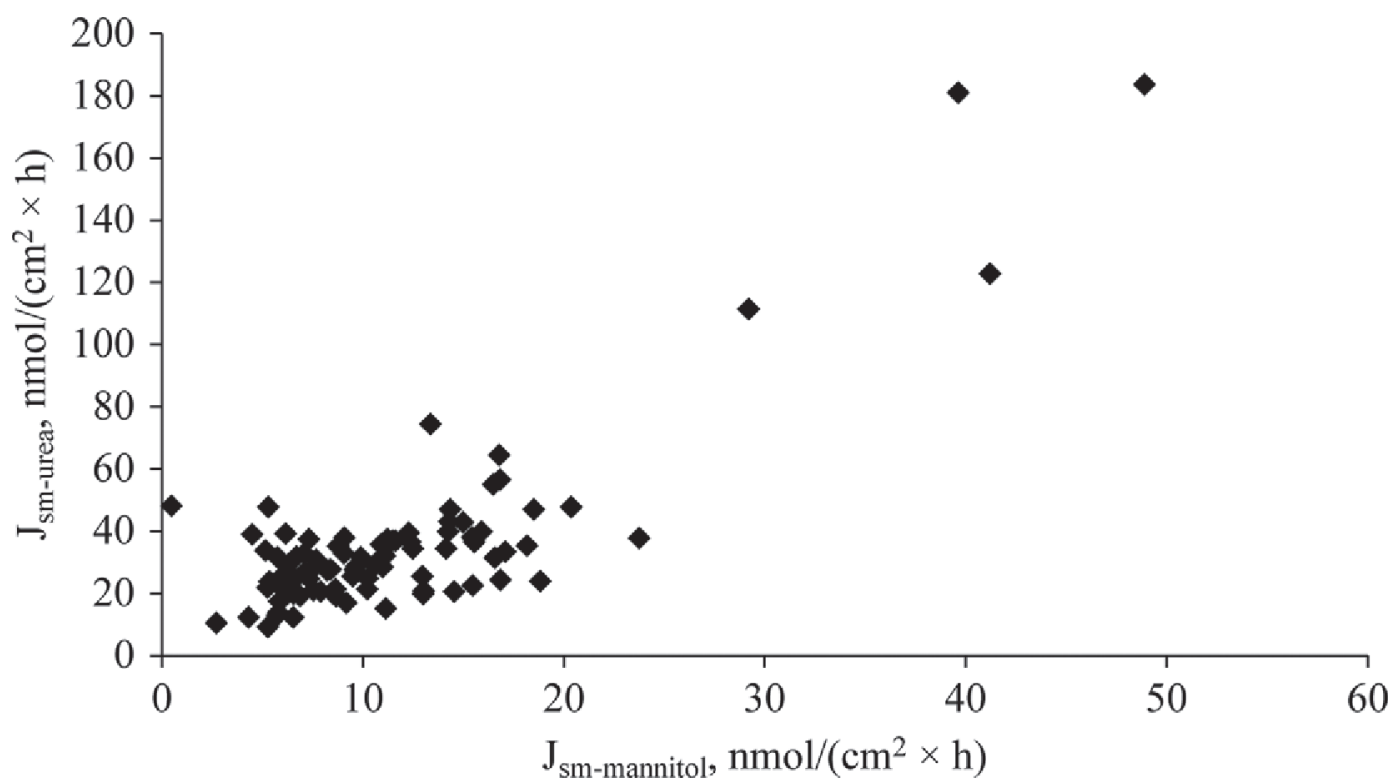

Figure 2. Relationship between serosal-to-mucosal flux of mannitol $\left(\mathrm{J}_{\text {sm-mannitol }}\right)$ and total inhibitor-insensitive serosal-to-mucosal flux of urea $\left(\mathrm{J}_{\text {sm-urea }}\right)$ in ruminal epithelia collected from Holstein steer calves after an abrupt change in diet fermentability $(\mathrm{r}=0.89 ; P<0.001)$.

\section{Diet Effects on UT-B and AQP mRNA Abundance in Ruminal Epithelium}

The mRNA expression of UT-B $(P=0.007)$ and AQP-3 $(P=0.001)$ in ruminal epithelium increased linearly as the duration of adaptation to the MGD increased (Table 3$)$. For AQP-7 $(P=0.008)$ and AQP-10
$(P=0.009)$, gene transcript abundance in animals that were fed the MGD diet for $21 \mathrm{~d}$ was greater compared with that of the CON animals. Total $J_{\text {sm-urea }}$ was significantly correlated with mRNA abundance of both AQP$3(\mathrm{r}=0.72 ; P=0.011)$ and UT-B $(\mathrm{r}=0.7 ; P=0.019$; data not shown). However, the correlation relationships between $\mathrm{NiCl}_{2}$-sensitive $\mathrm{J}_{\text {sm-urea }}$ and mRNA abundance

Table 2. Serosal-to-mucosal fluxes of urea $\left(\mathrm{J}_{\text {sm-urea }}\right)$ and mannitol $\left(\mathrm{J}_{\text {sm-mannitol }}\right)$, tissue conductance $\left(\mathrm{G}_{\mathrm{t}}\right)$, and short-circuit current $\left(\mathrm{I}_{\mathrm{sc}}\right)$ in ruminal epithelial tissues obtained from Holstein steer calves after an abrupt change in diet fermentability

\begin{tabular}{|c|c|c|c|c|c|c|c|c|c|c|}
\hline \multirow[b]{2}{*}{ Item } & \multicolumn{5}{|c|}{ Treatment $^{1}$} & \multirow[b]{2}{*}{ SEM } & \multicolumn{4}{|c|}{ Contrast ( $P$-value $)$} \\
\hline & $\mathrm{CON}$ & G3 & G7 & G14 & G21 & & $\begin{array}{c}\mathrm{CON} \\
\text { vs. G21 }\end{array}$ & Linear & Quadratic & Cubic \\
\hline Total & 107.7 & 112.6 & 112.8 & 122.8 & 144.2 & 14.5 & 0.09 & 0.08 & 0.60 & 0.85 \\
\hline $\mathrm{NiCl}_{2}$-insensitive ${ }^{2}$ & 77.9 & 79.4 & 74.2 & 106.9 & 108.1 & 12.4 & 0.11 & 0.15 & 0.51 & 0.63 \\
\hline $\mathrm{NiCl}_{2}$-sensitive ${ }^{2}$ & 29.7 & 14.2 & 20.7 & 18.7 & 37.5 & 16.8 & 0.07 & 0.55 & 0.31 & 0.84 \\
\hline Total-insensitive $^{4}$ & 27.1 & 38.6 & 26.1 & 33.2 & 58.7 & 5.9 & 0.86 & 0.11 & 0.76 & 0.69 \\
\hline Total-sensitive $^{4}$ & 92.5 & 86.2 & 95.1 & 93.8 & 109.1 & 12.4 & 0.99 & 0.22 & 0.52 & 0.95 \\
\hline $\mathrm{J}_{\mathrm{sm}-\mathrm{mannitol}}, \mathrm{nmol} /\left(\mathrm{cm}^{2} \times \mathrm{h}\right)$ & 15.8 & 17.0 & 17.6 & 19.5 & 19.8 & 1.63 & 0.14 & 0.06 & 0.53 & 0.81 \\
\hline $\mathrm{G}_{\mathrm{t}}, \mathrm{mS} / \mathrm{cm}^{2}$ & 3.46 & 3.38 & 2.80 & 3.27 & 3.20 & 0.29 & 0.37 & 0.61 & 0.23 & 0.41 \\
\hline $\mathrm{I}_{\mathrm{sc}}, \mathrm{mA}$ & $11.7^{\mathrm{ab}}$ & $17.5^{\mathrm{a}}$ & $17.5^{\mathrm{a}}$ & $10.0^{\mathrm{b}}$ & $13.9^{\mathrm{ab}}$ & 2.63 & 0.32 & 0.50 & 0.64 & 0.02 \\
\hline
\end{tabular}

${ }^{1}$ Treatments: $\mathrm{CON}=$ control diet $(91.5 \%$ hay and $8.5 \%$ vitamin and mineral supplement; $10.6 \% \mathrm{CP}, 4.1 \%$ starch, $48.4 \% \mathrm{NDF})$; G3, G7, G14, and G21 = moderate grain diet (41.5\% barley grain, $50 \%$ hay, and $8.5 \%$ vitamin and mineral; $11.4 \% \mathrm{CP}, 24.6 \%$ starch, $33.5 \%$ NDF) fed for 3 , 7,14 , or 21 d., respectively.

${ }^{2} \mathrm{NiCl}_{2}$-insensitive $\mathrm{J}_{\text {sm-urea }}$ equal to flux measurement after addition of $\mathrm{NiCl}_{2} ; \mathrm{NiCl}_{2}$-sensitive $\mathrm{J}_{\text {sm-urea }}$ equal to the inhibitable portion subtracted from the total flux.

${ }^{3}$ Phloretin-insensitive $\mathrm{J}_{\text {sm-urea }}$ equal to flux measurement after addition of phloretin; phloretin-sensitive $\mathrm{J}_{\text {sm-urea }}$ equal to the inhibitable portion subtracted from the total flux.

${ }^{4}$ Total-insensitive $\mathrm{J}_{\text {sm-urea }}$ equal to flux measurement after both $\mathrm{NiCl}_{2}$ and phloretin were added to chamber; total sensitive $\mathrm{J}_{\text {sm-urea }}$ equal to the inhibitable portion from both $\mathrm{NiCl}_{2}$ and phloretin, subtracted from the total flux. 
Table 3. The mRNA abundance (fold-change relative to control) for urea transporter B (UT-B) and aquaporins (AQP) in ruminal epithelial tissues obtained from Holstein steer calves after an abrupt change in diet fermentability

\begin{tabular}{|c|c|c|c|c|c|c|c|c|c|c|}
\hline \multirow[b]{2}{*}{ Item } & \multicolumn{5}{|c|}{ Treatment $^{1}$} & \multirow[b]{2}{*}{ SEM } & \multicolumn{4}{|c|}{ Contrast ( $P$-value) } \\
\hline & $\mathrm{CON}$ & G3 & G7 & G14 & G21 & & $\begin{array}{c}\text { CON } \\
\text { vs. G21 }\end{array}$ & Linear & Quadratic & Cubic \\
\hline AQP-3 & 1.00 & 1.55 & 2.40 & 4.47 & 4.68 & 0.72 & $<0.01$ & $<0.01$ & 0.45 & 0.47 \\
\hline AQP-7 & 1.00 & 0.03 & 0.04 & 0.13 & 0.15 & 0.29 & $<0.01$ & 0.20 & 0.12 & 0.18 \\
\hline AQP-10 & 1.00 & 0.13 & 0.11 & -0.02 & 0.01 & 0.32 & $<0.01$ & 0.09 & 0.17 & 0.38 \\
\hline UT-B & 1.00 & 1.38 & 1.35 & 2.44 & 3.02 & 0.52 & $<0.01$ & $<0.01$ & 0.85 & 0.78 \\
\hline
\end{tabular}

${ }^{1}$ Treatments: $\mathrm{CON}=$ control diet $(91.5 \%$ hay and $8.5 \%$ vitamin and mineral supplement; $10.6 \% \mathrm{CP}, 4.1 \%$ starch, $48.4 \% \mathrm{NDF}) ; \mathrm{G} 3, \mathrm{G} 7, \mathrm{G} 14$, and G21 = moderate grain diet (41.5\% barley grain, $50 \%$ hay, and $8.5 \%$ vitamin and mineral; $11.4 \% \mathrm{CP}, 24.6 \%$ starch, $33.5 \%$ NDF) fed for 3 , 7, 14, or 21 d., respectively.

for AQP-3 $(\mathrm{r}=0.25 ; P=0.25)$ and phloretin-sensitive $\mathrm{J}_{\text {sm-urea }}$ and mRNA abundance of UT-B $(\mathrm{r}=0.28, P=$ 0.19) were not significant (data not shown).

\section{DISCUSSION}

In ruminants, UNS is an important mechanism to conserve $\mathrm{N}$ because plasma urea- $\mathrm{N}$ that passes into the GIT (particularly the rumen) can be recovered in microbial protein, thus contributing AA to the host animal (Fuller and Reeds, 1998). In recent years, therefore, research efforts have been directed toward improving our understanding of the nutritional and physiological mechanisms that regulate UNS. Recent important findings were (1) that carrier-mediated, facilitative UT-B proteins are expressed in ruminal epithelia of bovine (Marini and Van Amburgh, 2003; Stewart et al., 2005) and ovine (Marini et al., 2004); (2) that adding phloretin (an inhibitor of UT-B function) to mounted ruminal epithelia in Ussing chambers reduces $\mathrm{J}_{\text {sm-urea }}$, thus indicating that UT-B have a functional role in UNS (Stewart et al., 2005; Abdoun et al., 2010; Doranalli et al., 2011); and (3) that the ruminal expression of UT-B responds to changes in levels of dietary N (Marini and Van Amburgh, 2003; Ludden et al., 2009) and concentrate (Simmons et al., 2009). In nonruminant species, AQP-3, 7, 9, and 10 have been shown to be permeable to urea (Bagnasco, 2005); however, their role in UNS in ruminants is still unknown.

In the present study, we wanted to determine the relative functional roles of UT-B and AQP in the transepithelial movement of urea from blood into the rumen. Our approach was to conduct measurements of total and inhibitor-sensitive $\mathrm{J}_{\text {sm-urea }}$ using phloretin (Stewart et al., 2005; Abdoun et al., 2010) and $\mathrm{NiCl}_{2}$ (MacIver et al., 2009) as inhibitors for UT-B and AQP, respectively. Our results showed that $\mathrm{J}_{\text {sm-urea }}$ was markedly decreased (by as much as 54\%) when phloretin was added. These inhibitory effects of phloretin on $\mathrm{J}_{\text {sm-urea }}$ are in agreement with other studies (Stewart et al.,
2005; Abdoun et al., 2010; Doranalli et al., 2011) that reported magnitudes of inhibition ranging from 20 to $50 \%$. The addition of $\mathrm{NiCl}_{2}$ also markedly decreased $\mathrm{J}_{\text {sm-urea }}$ by $23 \%$, providing the first evidence to date that AQP might play a functional role in transepithelial urea transfer in ruminants. To our knowledge, Røjen et al. (2011) is the only published study that sought to relate AQP expression in ruminal epithelia to quantitative urea transfer across the rumen. In that study, no relationship was identified between AQP expression in ruminal epithelial tissue and urea extraction across the ruminal wall (measured using the venous-arterial difference technique; data reported in Kristensen et al., 2010), so those authors concluded that their results did not support a role of AQP in regulating urea movement across the rumen. Our results clearly show that a portion of urea flux occurs via facilitated diffusion through $\mathrm{NiCl}_{2}$-sensitive AQP. When phloretin and $\mathrm{NiCl}_{2}$ were added together, the extent of inhibition of $\mathrm{J}_{\text {sm-urea }}$ was $68 \%$ and additive, providing strong evidence that the phloretin- and $\mathrm{NiCl}_{2}$-sensititive movement of urea occurred via 2 distinct pathways.

Correlations between mRNA and protein abundance of UT-B and AQP have yielded mixed results when determining the relative roles of urea transport for each protein. Røjen et al. (2011) observed that mRNA abundances of AQP-3, 7, and 10 were significantly upregulated when lactating Holstein cows were fed a high-N diet, whereas mRNA abundance of UT-B was unaffected by dietary $\mathrm{N}$ intake. Conversely, Western blot analysis showed no change in abundance of AQP proteins, whereas abundance of UT-B was higher in animals fed the low-N diets. Those authors concluded that the role of AQP in transepithelial urea transport was limited; however, even though mRNA and protein abundance for UT-B and AQP were assessed, the functional roles of these proteins in urea movement across the ruminal epithelia were not measured in the study of Røjen et al. (2011). In nonruminant species, it is known that long- and short-term regulation of AQP is 
affected by vasopressin levels in the circulating blood (Rojek et al., 2008); however, the signaling pathway by which AQP-3 in particular is affected in the short term is unclear because AQP-3 is not found in the cytosol, leading researchers to believe that minor changes in protein structure allow for activation or deactivation of this membrane protein (Ishibashi et al., 1997). It is known that increases in blood osmolarity have been associated with dehydration, resulting in increases in arginine-vasopressin secretion (Robertson and Athar, 1976). Although Schurmann (2014) was unable to detect significant changes in plasma osmolarity, animals fed the MGD had numerically higher plasma osmolarity concentrations than those fed the control diet in the current study. This was in agreement with past research demonstrating that when feeding fermentable carbohydrates to ruminants, ruminal osmolality increases (Owens et al., 1998). In the current study, we observed that a positive relationship between AQP-3 and UT-B mRNA abundance exists with total $\mathrm{J}_{\mathrm{sm}-}$ urea; however, the mechanism by which this increased gene expression and functional adaptation occurred is unclear. Increases in AQP-3 may have been mediated by changes in plasma osmolarity due to the increase in fermentable carbohydrate in the diet, with AQPmediated $\mathrm{J}_{\text {sm-urea }}$ being a side effect of osmotic regulatory pathways due to the primary role of AQP in the maintenance of osmotic balance.

It is well established that the entry of urea from blood into the rumen increases when ruminants are fed diets that are high in ruminally fermentable carbohydrate (RFC; Huntington, 1989; Theurer et al., 2002). Because plasma urea-N concentration typically decreases when ruminants are fed diets high in RFC, Abdoun et al. $(2006,2010)$ suggested that the observed stimulatory effects of dietary RFC on urea transfer to the rumen could be attributed to increased permeability of the ruminal epithelia to urea in response to increasing ruminal concentrations of short-chain fatty acids. As increasing concentrations of short-chain fatty acids are indicative of active fermentation activities in the rumen, greater rates of urea transfer will coincide with increasing demands for $\mathrm{N}$ to support microbial growth (Abdoun et al., 2006, 2010). However, to our knowledge, no published studies have investigated the rate of functional adaptation in ruminal urea transfer when ruminants are exposed to diets high in RFC. In addition, it is not known if functional adaptation involves changes in UT-B and AQP function. Our results showed a linear increase in total $\mathrm{J}_{\text {sm-urea }}$ as the length of exposure to dietary concentrate increased, with a $25 \%$ increase in $\mathrm{J}_{\mathrm{sm} \text {-urea }}$ by $\mathrm{d} 21$. These results confirm that feeding more concentrate to increase ruminal energy supply has stimulatory effects on urea secretion into the rumen, as has been reported by others (Huntington, 1989; Theurer et al., 2002). This response has been attributed, in part, to a decrease in ruminal $\mathrm{NH}_{3} \mathrm{~N}$ concentration arising from more-efficient microbial sequestration of $\mathrm{NH}_{3}-\mathrm{N}$ as more energy is available. Others (Kennedy and Milligan, 1980; Doranalli et al., 2011) reported a negative correlation between ruminal $\mathrm{NH}_{3-}$ $\mathrm{N}$ concentration and urea- $\mathrm{N}$ transfer into the rumen. Moreover, urea- $\mathrm{N}$ transfer into the rumen is facilitated by bacterial urease activity, which maintains a favorable concentration gradient (Rémond et al., 1996), and urease activity is negatively correlated with ruminal $\mathrm{NH}_{3}-\mathrm{N}$ concentration (Cheng and Wallace, 1979). In the present study, we observed a quadratic decrease in ruminal $\mathrm{NH}_{3}-\mathrm{N}$ concentration as the length of exposure to dietary concentrate increased up to $21 \mathrm{~d}$, and this could have increased the ruminal epithelium's permeability to urea.

Despite the linear increase in total $\mathrm{J}_{\text {sm-urea }}$ with exposure to dietary concentrate, we did not observe any changes in phloretin-sensitive (i.e., UT-B-mediated), $\mathrm{NiCl}_{2}$-sensitive (i.e., AQP-mediated), and total inhibitor-sensitive $\mathrm{J}_{\mathrm{sm} \text {-urea }}$. Across treatments, it was noteworthy that total inhibitor-sensitive $\mathrm{J}_{\text {sm-urea }}$ accounted for $80 \%$ of total $\mathrm{J}_{\text {sm-urea }}$ with no treatment effects on $\mathrm{G}_{\mathrm{t}}$. With inhibitor-insensitive $\mathrm{J}_{\text {sm-urea }}$ being highly correlated with $\mathrm{J}_{\text {sm-mannitol }}$, the remaining $\mathrm{J}_{\text {sm-urea }}(20 \%$ of total $\mathrm{J}_{\mathrm{sm} \text {-urea }}$ ) might be attributed to paracellular or hydrophilic movement of urea. When taken together, these data point to transcellular pathways for the passage of urea from blood into the rumen that are mediated via specific proteins (UT-B and AQP). In conjunction with our observations on inhibitor-sensitive $\mathrm{J}_{\text {sm-urea, }}$, we observed that prolonged exposure to dietary concentrate upregulated the mRNA expression of UT-B and AQP-3 in ruminal epithelia. In support of our findings, others have observed an increase in UT-B mRNA expression in ruminal epithelia when steers were fed a concentratebased rather than a forage-based diet (Simmons et al., 2009) or when energy intake increased in transition dairy cows (Røjen et al., 2008). Changes in UT-B mRNA expression have also been reported with other dietary factors such as dietary $\mathrm{N}$ concentration (Marini and Van Amburgh, 2003), suggesting that these alterations in UT-B expression could be responsible for the changes in urea secretion into the rumen that have been reported with various dietary manipulations (Reynolds and Kristensen, 2008). Of the AQP that are permeable to urea, only the mRNA expression of AQP-3 in ruminal epithelia was upregulated with prolonged exposure to dietary concentrate. We are not aware of any published studies that have reported AQP expression in ruminal epithelia when dietary concentrate is manipulated; however, Røjen et al. (2011) observed that 
mRNA expression of AQP-3, 7, and 10 were greater in cows fed a high- $\mathrm{N}$ diet compared with those fed a low$\mathrm{N}$ diet. In the present study, we observed only small, nonsignificant differences in $\mathrm{N}$ intakes across dietary treatments, so it is unlikely that the changes in AQP expression that we observed could be related to $\mathrm{N}$ intake. In nonruminants, AQP-3 has been shown to be capable of transporting small amounts of urea; thus, its upregulation in the present study could be responsible for the changes in $\mathrm{J}_{\mathrm{sm} \text {-urea }}$ with prolonged exposure to concentrate. Our hypothesis that the increase in $\mathrm{J}_{\text {sm-urea }}$ that has been observed in ruminants fed more fermentable carbohydrates is mediated via changes in UT-B and AQP function is supported by the increased expression of UT-B and AQP-3 in ruminal epithelia and the positive correlations between $\mathrm{J}_{\text {sm-urea }}$ and UT-B and AQP-3 expression. However, it should also be noted that a significant portion of the increase in $\mathrm{J}_{\text {sm-urea }}$ was due to paracellular urea transport. Across treatments, phloretin-sensitive and $\mathrm{NiCl}_{2}$-sensitive $\mathrm{J}_{\text {sm-urea }}$ accounted for 75 and $25 \%$, respectively, of total inhibitor-sensitive $\mathrm{J}_{\text {sm-urea }}$, suggesting that the functional role of UT-B in urea secretion into the rumen appears to be more quantitatively important than that of AQP.

Studies examining the role of AQP in other tissues, primarily mammalian kidney, have also noted the important functions of AQP in urea transport (Rojek et al., 2008). Zhao et al. (2006) observed that mRNA abundance of AQP-3 was significantly increased in mice after an abrupt dose of $300 \mu \mathrm{mol}$ of urea, and a significant increase in AQP-3-mediated urea transport. They also noted that in relation to UT-A abundance, mRNA abundance for AQP-3 and UT-B were increased. This is in agreement with the current study where UT-B accounted for a greater proportion of the total $\mathrm{J}_{\text {sm-urea }}$ than that of AQP-3, possibly because of the primary roles of AQP in water movement compared with the transport of urea. Conversely, it is thought that the marked increase in placental urea permeability from 60 to $100 \mathrm{~d}$ of gestation is due to the increases in AQP-3 expression (Johnston et al., 2000) in ovine placental tissues. Grether-Beck et al. (2012) noted that topical application of urea to human skin stimulated both UT-A and UT-B, as well as expression of AQP-3, 7, and 9. Based on these previous studies, it is clear that AQP play a role in transepithelial movement of urea across different types of epithelial tissues, and it appears that AQP-3 is the most active.

To our knowledge, this study is the first to demonstrate that AQP play a functional role in the transepithelial movement of urea from blood into the rumen, and that both UT-B and AQP account for most of the passage of urea into the rumen. This study also showed that exposure to dietary concentrate produces changes in UT-B and AQP expression in ruminal epithelia that might be responsible for the changes in urea entry that have been reported previously. The regulation of UT-B and AQP expression appears to be a major point of control for UNS, so additional research is needed to fully understand how these urea transport proteins are regulated.

\section{ACKNOWLEDGMENTS}

The authors thank staff of the Livestock Research Building, University of Saskatchewan, for assistance with animal care, as well as G. Gratton (University of Saskatchewan) for her assistance in Ussing chamber measurements. This research was supported by the Natural Sciences and Engineering Research Council of Canada (NSERC).

\section{REFERENCES}

Abdoun, K., F. Steumpff, I. Rabbani, and H. Martens. 2010. Modulation of urea transport across sheep rumen epithelium in vitro by SCFA and $\mathrm{CO}_{2}$. Am. J. Physiol. Gastrointest. Liver Physiol. 298:G190-G202.

Abdoun, K., F. Stumpff, and H. Martens. 2006. Ammonia and urea transport across the rumen epithelium: A review. Anim. Health Res. Rev. 7:43-59.

Bagnasco, S. M. 2005. Role and regulation of urea transporters. Pflugers Arch. 450:217-226.

Broderick, G. A., and J. H. Kang. 1980. Automated simultaneous determination of ammonia and total amino acids in ruminal fluid and in vitro media. J. Dairy Sci. 63:64-75.

Cheng, K. J., and R. J. Wallace. 1979. The mechanism of passage of endogenous urea through the rumen wall and the role of ureolytic epithelial bacteria in the urea flow. Br. J. Nutr. 42:553-557.

Chomczynski, P., and N. Sacchi. 1987. Single-step method of RNA isolation by acid guanidinium thiocyanate-phenol-chloroform extraction. Anal. Biochem. 162:156-159.

Delgado-Elorduy, A., C. B. Theurer, J. T. Huber, A. Alio, O. Lozano, M. Sadik, P. Cuneo, H. D. De Young, I. J. Simas, J. E. P. Santos, L. Nussio, C. Nussio, K. E. Webb Jr., and H. Tagari. 2002. Splanchnic and mammary nitrogen metabolism by dairy cows fed steam-rolled or steam-flaked corn. J. Dairy Sci. 85:160-168.

Doranalli, K., G. B. Penner, and T. Mutsvangwa. 2011. Feeding oscillating dietary crude protein concentrations increases nitrogen utilization in growing lambs and this response is partly attributable to increased urea transfer to the rumen. J. Nutr. 141:560-567.

Egan, A. R., K. Boda, and J. Varady. 1986. Regulation of nitrogen metabolism and recycling. Pages 386-402 in Control of Digestion and Metabolism in Ruminants. L. P. Milligan, W. L. Grovum and A. Dobson, ed. Prentice-Hall, Englewood Cliffs, NJ.

Fuller, M. F., and P. J. Reeds. 1998. Nitrogen recycling in the gut. Annu. Rev. Nutr. 18:385-411.

Gozho, G. N., M. R. Hobin, and T. Mutsvangwa. 2008. Interactions between barley grain processing and source of supplemental dietary fat on nitrogen metabolism and urea-nitrogen recycling in dairy cows. J. Dairy Sci. 91:247-259.

Grether-Beck, S., I. Felsner, H. Brenden, Z. Kohne, M. Majora, A. Marini, T. Jaenicke, M. Rodriguez-Martin, C. Trullas, M. Hupe, P. M. Elias, and J. Krutmann. 2012. Urea uptake enhances barrier function and antimicrobial defense in humans by regulating epidermal gene expression. J. Invest. Dermatol. 132:1561-1572.

Harmeyer, J., and H. Martens. 1980. Aspects of urea metabolism in ruminants with reference to the goat. J. Dairy Sci. 63:1707-1728. 
Huntington, G. B. 1989. Hepatic urea synthesis and site and rate of urea removal from blood of beef steers fed alfalfa hay or a high concentrate diet. Can. J. Anim. Sci. 69:215-223.

Huntington, G. B., and S. L. Archibeque. 1999. Practical aspects of urea and ammonia metabolism in ruminants. J. Anim. Sci. 78:742-749.

Ishibashi, K., S. Sasaki, K. Fushimi, T. Yamamoto, M. Kuwahara, and F. Marumo. 1997. Immunolocalization and effect of dehydration on AQP3, a basolateral water channel of kidney collecting ducts. Am. J. Physiol. 272:F235-F241.

Johnston, H., I. Koukoulas, K. Jeyaseelan, A. Armugam, L. Earnest, R. Baird, N. Dawson, T. Ferraro, and E. M. Wintour. 2000. Ontogeny of aquaporins 1 and 3 in ovine placenta and fetal membranes. Placenta 21:88-99.

Kennedy, P. M., and L. P. Milligan. 1980. The degradation and utilization of endogenous urea in the gastrointestinal tract of ruminants: a review. Can. J. Anim. Sci. 60:205-221.

Kristensen, N. B., A. C. Storm, and M. Larsen. 2010. Effect of dietary nitrogen content and intravenous urea infusion on ruminal and portal-drained visceral extraction of arterial urea in lactating Holstein cows. J. Dairy Sci. 93:2670-2683.

Lapierre, H., and G. E. Lobley. 2001. Nitrogen recycling in the ruminant: A review. J. Dairy Sci. 84(E. Suppl.):E223-E226.

Livak, K. J., and T. D. Schmittgen. 2001. Analysis of relative gene expression data using real-time quantitative PCR and the $2^{-\Delta \Delta \mathrm{CT}}$ method. Methods 25:402-408.

Lobley, G. E., D. M. Bremner, and G. Zuur. 2000. Effects of diet quality on urea fates in sheep as assessed by refined, non-invasive [15N $15 \mathrm{~N}]$ urea kinetics. Br. J. Nutr. 84:459-468.

Ludden, P. A., R. M. Stohrer, K. J. Austin, R. L. Atkinson, E. L. Belden, and H. J. Harlow. 2009. Effect of protein supplementation on expression and distribution of urea transporter-B in lambs fed low-quality forage. J. Anim. Sci. 87:1354-1365.

Ma, T., and A. S. Verkman. 1999. Aquaporin water channels in gastrointestinal physiology. J. Physiol. 517:317-326.

MacIver, B., C. P. Cutler, J. Yin, M. G. Hill, M. L. Zeidel, and W. G. Hill. 2009. Expression and functional characterization of four aquaporin water channels from the European eel (Anguilla anguilla). J. Exp. Biol. 212:2856-2863.

Marini, J. C., J. M. Klein, J. M. Sands, and M. E. Van Amburgh. 2004. Effect of nitrogen intake on nitrogen recycling and urea transporter abundance in lambs. J. Anim. Sci. 82:1157-1164.

Marini, J. C., and M. E. Van Amburgh. 2003. Nitrogen metabolism and recycling in Holstein heifers. J. Anim. Sci. 81:545-552.

Marsh, W. H., B. Fingerhunt, and E. Kirsch. 1957. Determination of urea $\mathrm{N}$ with the diacetyl method and an automatic dialyzing apparatus. Am. J. Clin. Pathol. 28:681-688.

Muscher, A. S., B. Schroder, G. Breves, and K. Huber. 2010. Dietary nitrogen reduction enhances urea transport across goat rumen epithelium. J. Anim. Sci. 88:3390-3398.

Ontsouka, E. C., B. Korczak, H. M. Harmon, and J. W. Blum. 2004. Real-time PCR quantification of bovine lactase mRNA localization in the gastrointestinal tract of milk-fed calves. J. Dairy Sci. 87:4230-4237.

Owens, F. N., D. S. Secrist, W. J. Hill, and D. R. Gill. 1998. Acidosis in cattle: A review. J. Anim. Sci. 76:275-286.

Rémond, D., F. Meschy, and R. Boivin. 1996. Metabolites, water and mineral exchanges cross the rumen wall: Mechanisms and regulation. Ann. Zootech. 45:97-119.
Reynolds, C. K., and N. B. Kristensen. 2008. Nitrogen recycling through the gut and the nitrogen economy of ruminants: An asynchronous symbiosis. J. Anim. Sci. 86(E. Suppl.):E293-E305.

Ritzhaupt, A., G. Breves, B. Schroder, C. G. Winckler, and S. P. Shirazi-Beechey. 1997. Urea transport in gastrointestinal tract of ruminants: effect of dietary nitrogen. Biochem. Soc. Trans. 25:S490. (Abstr.)

Ritzhaupt, A., I. S. Wood, A. A. Jackson, B. J. Moran, and S. P. Shirazi-Beechey. 1998. Isolation of RT-PCR fragment from human colon and sheep rumen RNA with nucleotide sequence similarity to human and rat urea transporter isoforms. Biochem. Soc. Trans. 26:S122. (Abstr.)

Robertson, G. L., and S. Athar. 1976. The interaction of blood osmolality and blood volume in regulating plasma vasopressin in man J. Clin. Endocrinol. Metab. 42:613-620.

Robinson, P. H., M. Gill, and J. J. Kennelly. 1997. Influence of time of feeding a protein meal on ruminal fermentation and forestomach digestion in dairy cows. J. Dairy Sci. 80:1366-1373.

Rojek, A., J. Praetorius, J. Frøkiaer, S. Nielsen, and R. A. Fenton. 2008. A current view of mammalian aquaglyceroporins. Annu. Rev. Physiol. 70:301-327.

Røjen, B. A., S. B. Poulsen, P. K. Theil, R. A. Fenton, and N. B. Kristensen. 2011. Effects of dietary nitrogen concentration on messenger RNA expression and protein abundance of urea transporter-B and aquaporins in ruminal papillae from lactating Holstein cows. J. Dairy Sci. 94:2587-2591.

Røjen, B. A., P. K. Theil, M. Larsen, and N. B. Kristensen. 2008. Correlation between UT-B mRNA abundance in ruminant epithelia and net portal flux of urea in transition dairy cows. J. Anim. Sci. 86(E-Suppl. 2):T260. (Abstr.).

Schurmann, B. L. 2014. Functional adaptation of the ruminal epithelium. MSc Thesis. University of Saskatchewan, Saskatoon, Saskatchewan, Canada.

Siddons, R. C., J. V. Nolan, D. E. Beever, and J. C. MacRae. 1985. Nitrogen digestion and metabolism in sheep consuming diets containing contrasting forms and levels of N. Br. J. Nutr. 54:175-187.

Simmons, N. L., A. S. Chaudhry, C. Graham, E. S. Scriven, A. Thistelthwaite, C. P. Smith, and G. S. Stewart. 2009. Dietary regulation of ruminal bovine UT-B urea transporter expression and localization. J. Anim. Sci. 87:3288-3299.

Stewart, G. S., C. Graham, S. Cattell, T. P. L. Smith, N. L. Simmons, and C. P. Smith. 2005. UT-B is expressed in the bovine rumen: Potential role in ruminal urea transport. Am. J. Physiol. Regul. Integr. Comp. Physiol. 289:R605-R612.

Sunny, N. E., S. L. Owens, R. L. Baldwin VI, S. W. El-Kadi, R. A. Kohn, and B. J. Bequette. 2007. Salvage of blood urea nitrogen in sheep is highly dependent upon plasma urea concentration and the efficiency of capture within the digestive tract. J. Anim. Sci. 85:1006-1013.

Theurer, C. B., G. B. Huntington, J. T. Huber, R. S. Swingle, and J. A. Moore. 2002. Net absorption and utilization of nitrogenous compounds across ruminal, intestinal, and hepatic tissues of growing beef steers fed dry-rolled or steam-flaked sorghum grain. J. Anim. Sci. 80:525-532.

Vercoe, J. E. 1969. The transfer of nitrogen from the blood to the rumen of cattle. Aust. J. Agric. Res. 20:191-197.

Zhao, D., L. Bankir, L. Qian, D. Yang, and B. Yang. 2006. Urea and urine concentrating ability in mice lacking AQP 1 and 3. Am. J. Physiol. Renal Physiol. 291:F429-F438. 